\section{Assessment of the Drug/Drug Interaction in the Prescriptions of the Diabetes Mellitus at Tertiary Care Hospital of Larkana Sindh, Pakistan}

\section{Abstract}

Purpose: The purpose of this study was to assess the possible drug/drug interaction in the prescriptions of the diabetic patients.

Methodology and study design: A descriptive based study was carried out. The 400 prescriptions were taken into the account using the sample purposive technique. The prescriptions of the diabetic patients were taken into the account and the study was made with the reference of the DDI software and the Lexicomp books. Those patients who had disease other than diabetes mellitus were excluded from the study. Only the interested patients were included in the study.

Study site: The study was carried out at the tertiary care Hospital of Larkana, Sindh, Pakistan.

Results: From the total $61.25 \%$ male patients were taken and the female \% age was about $38.57 \%$. Furthermore, the area wise distribution of the sample was also made and in this regard $52.75 \%$ were belonging to the urban area and the remaining $47.26 \%$ were from the rural areas of Sindh, Pakistan.

Conclusion: From the study it was concluded that the numerous drug/drug interaction were observed in the prescriptions of the diabetic patients.

Keywords: Diabetes; Drug/Drug interactions; Prescriptions

Received: January 02, 2019; Accepted: January 22, 2019; Published: January 25, 2019

\section{Introduction}

The Definition of "D/D interactions" can be said that alter in kinetics of the drug which is caused by another drug [1,2]. There could be different effects of the drug/drug interaction especially the toxicity and the decreased pharmacological effects are the essential, such as the interaction between an antihypertensive drug and a diuretic. Grave outcomes due to drug-drug interactions were observed when the drugs were administered in the form of a combination but not all interactions were held to be serious at a similar rate when were compared to others $[3,4]$. How much severe was the outcome of the adverse event on this basis the DDIs are being assessed. Diabetes is derived from Greek word "Siphon" means sweet as honey [5]. And it was believed that taste of urine was the major part to diagnose the diabetes [6]. If the person had frequent urination with sweet taste to be have diabetes, and this type of habit of checking diabetes continued until Insulin was

\section{Mangi AA ${ }^{1 *}$, Khan $\mathrm{H}^{1}$, Fazal- ur-Rehman ${ }^{1}$, Hashmatullah', Channa $\mathrm{TA}^{2}$, Shehzad MA ${ }^{1}$ and Khan MK'}

\section{Faculty of Pharmacy, Department of Pharmaceutical Chemistry, Gomal University, Dera Ismail Khan City, Khyber Pakhtunkhwa, Pakistan \\ 2 Department of Pharmacy, Shaheed Mohtarma Benazeer Bhutto Medical University (SMBBMU), Larkana, Sindh, Pakistan}

\section{*Corresponding author: \\ Dr. Altaf Ali Mangi}

\section{” pharmacistsindh41@gmail.com}

PhD Scholar, Faculty of Pharmacy, Department of Pharmaceutical Chemistry, Gomal University, Dera Ismail Khan City, Khyber Pakhtunkhwa, Pakistan.

Tel: +923313421263

Citation: Mangi AA, Khan H, Fazal-ur-Rehman, Hashmatullah, Channa TA, et al. (2019) Assessment of the Drug/Drug Interaction in the Prescriptions of the Diabetes Mellitus at Tertiary Care Hospital of Larkana Sindh, Pakistan . Insights Biomed Vol.4 No.1:2

not discovered. There are so many signs for diagnosis of diabetes that may include; polydipsia, polyphagia, polyuria, fatigue, blurred vision, weight loss, frequent and slow healing infection including vaginal, skin and bladder infection, dry and itchy skin, loosing feeling in your feet, feeling numbness and pins in your feet $[7,8]$. The patients diagnosed with the diabetes mellitus may fall prey of the polypharmacy and. these include medications for dyslipidemia, hypertension, antiplatelet therapy, and glycemic control [9]. So many medications can be overwhelming, hence it is very significant to educate the patients regarding drug regimen and mostly the people remain very worried about the multiple drug therapy so in the prescription aid for the diabetic patients contained. There are different sorts of the diabetes mellitus 
like type 1 it is also called insulin dependent diabetes, it only develops in childhood at the age of 4 to 6 years, and the main reason behind this type of diabetes is totally diminishing of beta cells; which are responsible for the production of Insulin. And the diabetic people are managed by external usage of insulin for their entire life. Besides this there is type II diabetes mellitus [10-12]. It is also called insulin independent diabetes and it mostly happens after the age of 30-35 years and there are so many reasons for its development [13]. It may occur due to insulin resistance or insulin action or may be both. Many people in the world are diagnosed with Type II diabetes and still many are unknown and the gestational diabetes mellitus $[14,15]$. It is the only type of Diabetes that occurs only in females during the periods of gestation (Pregnancy) [16]. If Gestational diabetes occurs body cannot use sugar and starch (carbohydrates) for the production of energy. In the results body gain extra sugar in their systemic circulation (blood) [17-19]. this is very harmful for mother as well as for the fetus. According to research it is estimated that 1 out of 50 pregnant women having Gestational Diabetes, the actual cause of gestational diabetes is not known but women with GDM gain weight before pregnant. In case of the $D / D$ interaction the pharmacological effects of the drug are either decreased or the toxicity develops. The objective of the current study is to evaluate drug/drug reciprocity in treatment of diabetes mellitus $[20,21]$.

\section{Methodology}

The descriptive based stud made at a Tertiary Care Hospital of Larkana, Sindh, Pakistan. A total of 500 prescriptions were taken using the sample purposive technique. The study was carried out for the period of 6 months. Before starting the research, the verbal consent was taken from the patients by defining all the details of the study furthermore, all the acquired prescriptions were analyzed and assessed by help of standard references as Software for DDIs, Lexicomp, Drug knowledge website etc. Furthermore, the founded interactions were categorized as minor, moderate and major respectively.

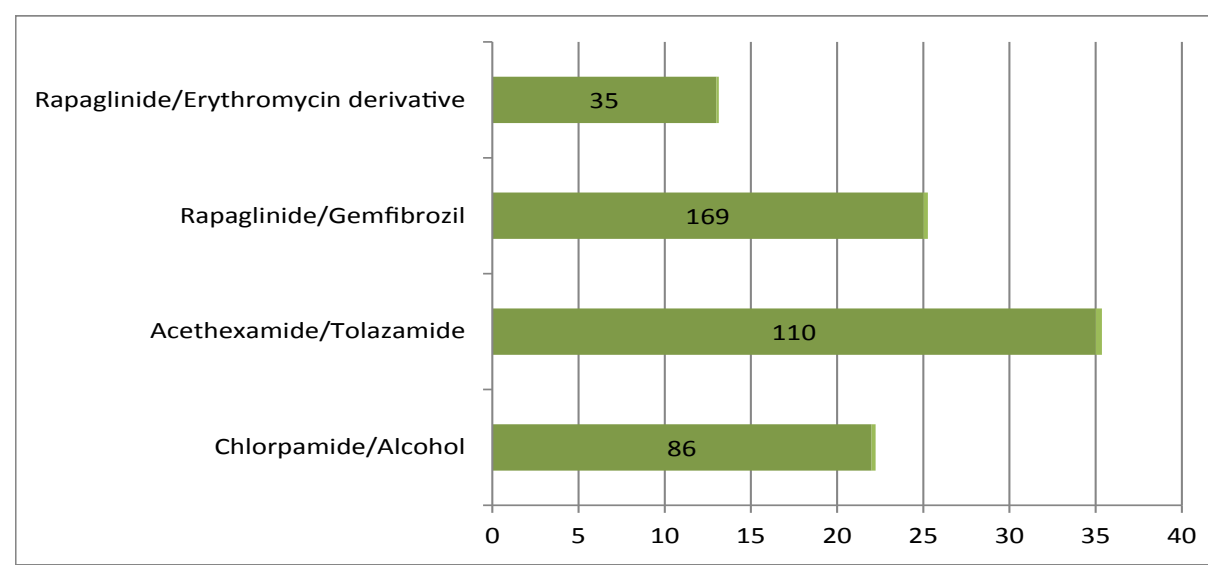

Figure 1 Diabetes drug/drug interactions.

Table 1 Gender wise distribution of sample.

\begin{tabular}{ccc}
\hline Gender & Number of Prescription & Percentage \\
Male & 245 & $61.25 \%$ \\
Female & 155 & $38.75 \%$ \\
\hline *From the total of 400 medication orders, 245 belonged to males and 155 to the female. &
\end{tabular}

Table 2 Area wise distribution of prescriptions.

\begin{tabular}{lcc} 
& No of Patients & Percentage \\
$\qquad \begin{array}{ll}\text { Area based distribution } \\
\text { Urban }\end{array}$ & 211 & $52.75 \%$ \\
\hline Rural & 189 & $47.25 \%$ \\
Total & 400 & $100 \%$ \\
*The area wise distribution of the sample. In this table it is shown that 211 patients belong to the urban areas whereas 189 belongs to the rural \\
areas.
\end{tabular}

Table 3 Drug/Drug interaction in the diabetes mellitus.

\begin{tabular}{|c|c|c|c|}
\hline Drugs & Prescription No & Percentage & Consequences \\
\hline Chlorpropamide/Alcohol & 86 & $21.5 \%$ & Facial flushing \\
\hline Acetohexamide/Tolazamide & 110 & $27.5 \%$ & Increased hypoglycemia \\
\hline Repaglinide/Gemfibrozil & 169 & $42.25 \%$ & Prolonged hypoglycemia \\
\hline Repaglinide/Erythromycin derivative & 35 & $8.75 \%$ & Reduced efficacy of Repaglinide \\
\hline
\end{tabular}




\section{Statistical analysis}

Every solution was assessed, and information was broken down by utilizing SPSS programming adaptation 20.

\section{Discussion}

The area of interest in this study is to evaluate the drug/drug interaction used simultaneously in a single prescription (polypharmacy) at tertiary care hospital of Larkana. Moreover, different studies have been done regarding the significance of the DDIs in this study main object of current study is to lay the emphasis the on the prevalence of medication interactions among the poly-pharmacy practiced medication-orders. Subsequently poly-pharmacy practice is described as the multiple prescribed medications in a single physician's order. Moreover, as the polypharmacy prescription is prescribed there are more risks for the drug/drug interaction. Diabetes is chronic disorder in which body cannot produce sufficient amount of energy due to lack of insulin activity or insulin secretion within the body. High level of glucose within systemic circulation may leads towards complication of diabetes which may be fatal. In the current study near 400 prescriptions were taken into the account. From the total $61.25 \%$ male patients were taken and the female \% age was about $38.57 \%$ (Table 1). Furthermore, the area wise distribution of the sample was also made and in this regard $52.75 \%$ were belonging to the urban area and the remaining $47.26 \%$ were from the rural areas of Sindh Pakistan (Table 2). Prescriptions containing the therapies of diabetes mellitus were taken into the study and the drug/drug interaction in the case files of the diabetic patients was assessed.

\section{References}

1 Liatis S, Marinou K, Tentolouris N, Pagoni S, Katsilambros N (2007) Usefulness of a new indicator test for the diagnosis of peripheral and autonomic neuropathy in patients with diabetes mellitus. Diabet Med 24: 1375-1380

2 Stevens MJ, Raffel DM, Allman KC, Dayanikli F, Ficaro E, et al. (1998) Cardiac sympathetic dysinnervation in diabetes: Implications for enhanced cardiovascular risk. Circulation 98: 961-968.

3 Milan Study on Atherosclerosis and Diabetes (MiSAD) Group (1997) Prevalence of unrecognized silent myocardial ischemia and its association with atherosclerotic risk factors in noninsulin-dependent diabetes mellitus. Am J Cardiol 79: 134-139.

4 Airaksinen KEJ, Koistinen MJ (1992) Association between silent coronary artery disease, diabetes, and autonomic neuropathy. Diabet Care 15: 288-292.

5 Ewing DJ, Boland O, Neilson JM, Cho CG, Clarke BF (1991) Autonomic neuropathy, QT interval lengthening, and unexpected deaths in male diabetic patients. Diabetologia 34: 182-185.

6 Langer A, Freeman MR, Josse RG, Armstrong PW (1995) Metaiodobenzylguanidine imaging in diabetes mellitus: assessment of cardiac sympathetic denervation and its relation to autonomic dysfunction and silent myocardial ischemia. J Am Coll Cardiol 25: 610-618.

7 Mathias CJ, Da Costa DF, Fosbraey P, Christensen NJ, Bannister R (1987) Hypotensive and sedative effects of insulin in autonomic failure. Br Med J 295: 161-163.
From this the Chlorpropamide/Alcohol interaction was found to be the 21.5 which resulted in the facial flushing, Acetohexamide/ Tolazamide these types of the interactions were noted to be the $27.5 \%$ and they caused the increased hypoglycemia. Repaglinide/ Gemfibrozil interactions were found to be the 42.25 and they resulted in the prolonged hypoglycemia. Apart from this the Repaglinide/Erythromycin derivative were found to be the $8.75 \%$ and they caused the reduced efficacy of Repaglinide (Table 3). The strong explanation behind current research was to address the DDIs in prescriptions of different physicians and consultants in Iran. Although the audit was coordinated for period of 2 years i.e., since 2007 till 2009. Each one of pharmaceuticals, suggested by specialists from 33 IMUs (Irani Medical Universities). One more study conducted in medicinal ward of one of the hospital of Bangalore by Jimmy OD et al. for a period of 9 months to evaluate drug/drug interactions in drug chart and it was made in medicinal ward, in their study, 230 patients were selected whereas in current research the sample size was 400 and 245 (61.25\%) male and 155 (38.75\%) females were selected (Figure 1).

\section{Conclusion}

From the study it was concluded that the numerous drug/drug interaction were observed in the prescriptions of the diabetic patients and the Subsequently, it was also found during the survey that most of the drug delivery sites and various wards had an ample shortage of Pharmacist which is again of a serious concern that no any person was available to judge the prescriptions and analyze the $D / D$ interactions among them.

8 Agardh CD, Cilio CM, Lethagen A (2005) Clinical evidence for the safety of GAD65 immunomodulation in adult-onset autoimmune diabetes. J Diabet Complicat 19: 238-246.

9 Landstedt-Hallin L, Arner P, Lins PE (1999) The role of sulphonylurea in combination therapy assessed in a trial of sulphonylurea withdrawal: Scandinavian Insulin-Sulphonylurea Study Group Research Team. Diabet Med 16: 827-834.

10 Dagogo-Jack SE, Craft S, Cryer PE (1993) Hypoglycemia-associated autonomic failure in insulin-dependent diabetes mellitus: Recent antecedent hypoglycemia reduces autonomic responses to, symptoms of, and defense against subsequent hypoglycemia. J Clin Invest 91: 819-828.

11 Feldman HA, Goldstein I, Hatzichristou DG, Krane RJ, McKinlay JB (1994) Impotence and its medical and psychosocial correlates: results of the Massachusetts Male Aging Study. J Urol 151: 54-61.

12 Farup CE, Leidy NK, Murray M, Williams GR, Helbers L, et al. (1998) Effect of domperidone on the healthrelated quality of life of patients with symptoms of diabetic gastroparesis. Diabet Care 21: 1699-1706.

13 Stansberry KB, Hill MA, Shapiro SA, Mc-Nitt PM, Bhatt BA, et al. (1997) Impairment of peripheral blood flow responses in diabetes resembles an enhanced aging effect. Diabet Care 20: 1711-1716.

14 Costa AJ (1991) Potential drug interactions in an ambulatory geriatric population. Fam Pract 8: 234-236.

15 Hansten PD (2003) Drug interaction management. Pharm World Sci 25: 94-97.

16 Mahmood M, Malone DC, Skrepnek GH, Abarka J, Armstrong EP, et 
al. (2007) Potential drug-drug interactions within veteran's affairs medical centers. Am J Health Syst Pharm 64: 1500-1505.

17 Merlo J, Liedholm H, Lindblad U, Bjorck-Linne A, Falt J, et al. (2001) Prescriptions with potential drug interaction dispensed at Swedish pharmacies in January 1999: A cross sectional study. Br Med J 323: 427-428.

18 Sameer D, Milind P (2011) Assessment of a drug interaction of antidepressants with other prescribed drugs. Asian J Pharm clin Res 4: 102-104.

19 Micromedex $^{\circledast}$ solutions (1995) Truven Health analytics (internet database). Greenwood village, colo, Thomson Reuters (Healthcare) Inc.

20 Jeyaraj DP, Sudhan P (2013) Stroke epidemiology and stroke care services in India. J Stroke 15: 128-134.

21 Eric R, Bates DM, Wei CL (2003) Drug-drug interactions involving antiplatelet agents. Eur Heart J 24: 1707-1709. 